\section{Summary of: Why individuals with HIV or diabetes do not disclose their medical history to the dentist: a qualitative analysis}

\author{
J. Edwards, ${ }^{* 1}$ G. Palmer, ${ }^{2}$ N. Osbourne ${ }^{3}$ and S. Scambler ${ }^{4}$ \\ VERIFIABLE CPD PAPER
}

FULL PAPER DETAILS

'Specialist in Special Care Dentistry. Department of Sedation and Special Care Dentistry. Guy's and St Thomas' Foundation NHS Trust. Floor 26, Tower Wing, Great Maze Pond, Guy's Hospital London, SE1 9RT;

${ }^{2}$ Consultant in Special Care Dentistry. Department of Community Special Care Dentistry. King's College NHS Trust, Dental Institute, ${ }^{3}$ Charge Nurse. Sexual Health Unit. King's College Hospital, ${ }^{4}$ Lecturer in Sociology, Department of Oral Health Services Research \&t Dental Public Health, GKT, Dental Institute King's College London, Caldecot Road, Denmark Hill, London, SE5 9RW.

${ }^{*}$ Correspondence to: Julie Edwards Email: juliea.edwards@nhs.net; Tel: 02071886066

Refereed Paper

Accepted 3 May 2013

DOI: $10.1038 /$ sj.bdj.2013.881

British Dental Journal 2013; 215: E10

\begin{abstract}
Introduction Evidence shows that some individuals with HIV or diabetes do not report their medical history to the dentist. Disclosure is important because these individuals can be at greater risk of oral disease. Aims and objectives The aim of this study is to provide greater understanding of why some individuals do not disclose HIV or diabetes to the dentist. Methods In-depth interviews were conducted with 20 participants (10 HIV \& 10 diabetes) based around the participant's diagnosis and disclosure history. Data were analysed using framework analysis. Results While a lack of disclosure can be found among those with a diagnosis of HIV and diabetes, it appears that the reasons behind disclosure, or lack thereof, are different for each. The reasons are based around: differences in age, understanding of diagnosis, experience of stigma, past disclosure behaviour, trust in dentists and experience of healthcare. Few individuals had discussed the effects of their diagnosis with their dentist or were advised on the importance of seeing a dentist. Discussion Individuals with chronic illness should be advised why it is important for the dentist to know their medical history and should be made to feel comfortable to disclose.
\end{abstract}

\section{EDITOR'S SUMMARY}

'It's a basic truth of the human condition that everybody lies. The only variable is about what.' These words, perhaps thankfully, are from a fictional character, Dr Greg House, the sardonic doctor played by Hugh Laurie in the popular television series, House M.D. Nevertheless, it is true that patients sometimes lie, often by omission, to medical professionals.

Patients may decide not to disclose an accurate medical history to their dentist for any number of reasons - they might be embarrassed, they might fear a negative reaction, may judge the information to be redundant or they may just forget. Indeed, we really don't fully understand what the real reasons are; particularly when it comes to chronic diseases such as diabetes and HIV. As the authors of this $B D J$ research paper point out, the evidence behind the reasons for lack of disclosure is now predominantly out-of-date.
As dental professionals this can be frustrating as disclosure of medical history is so important in allowing patients to be treated safely and effectively. Thus, the aim of the study outlined in this paper was to provide greater understanding of why patients often do not disclose chronic illnesses to their dentist. The authors outline qualitative research from an interview-based investigation involving ten patients with HIV and ten with diabetes.

Among other interesting results, the study confirms the role of stigma as one of the reasons behind lack of disclosure. The good news regarding HIV is that it appears that public opinion is improving with regard to those diagnosed with this illness. However, according to the those with diabetes interviewed in the study, it may be that a general negativity around diabetes is developing, possibly because of diabetes type 2's associations with obesity.

'Listen to your patient, he is telling you the diagnosis.' This is a quotation attributed to William Osler (1849-1919), often called the 'Father of Modern Medicine' for his contributions to medical education. The authors of this paper counsel that dentists should advise patients why it is important for them to disclose their full medical history and also reassure them that they, as medical professionals, can of course be trusted with this confidential information. This can but help the patient to 'tell you the diagnosis' so that you can be confident that you are managing their care effectively.

The full paper can be accessed from the $B D J$ website (www.bdj.co.uk), under 'Research' in the table of contents for Volume 215 issue 6.

Ruth Doherty Managing Editor DOI: 10.1038/sj.bdj.2013.910 


\section{TO ACCESS THE BDJ WEBSITE TO READ THE FULL PAPER:}

- BDA Members should go to www.bda.org.

- Click the 'login' button on the right-hand side and enter your BDA login details.

- Once you have logged in click the 'BDJ' tab to transfer to the BDJ website with full access.

IF YOUR LOGIN DETAILS DO NOT WORK:

- Get a password reminder: go to www.bda.org, click the login button on the right-hand side and then click the forgotten password link.

- Use a recommended browser: we recommend Microsoft Internet Explorer or Mozilla Firefox.

- Ensure that the security settings on your browser are set to recommended levels.

IF YOU HAVE NOT YET SIGNED UP TO USE THE BDA WEBSITE:

- Go to www.bda.org/getstarted for information on how to start using the BDA website.
IN BRIEF

- Investigates the reasons why patients don't disclose their medical history to the dentist.

- Discusses the importance of working with other healthcare professionals to promote oral health and improve disclosure.

- Provides advice for dentists on medical history taking.

\section{COMMENTARY}

We rely on patients to give us an accurate medical history. ${ }^{1}$ Worryingly it is clear that some patients deliberately do not tell us about serious medical conditions. Non-disclosure of HIV to dentists has been reported as high as $33 \%$. $^{2}$ Stigma associated with HIV is well recognised but in patients with diabetes it is perhaps surprising to see that non-disclosure and stigma are also present. In this qualitative study by Edwards et al. structured interviews were used to collect statements about the personal reasons and beliefs of patients. They have gained an interesting insight into why some patients do not disclose HIV or diabetes, which is much more informative than a quantitative study.

The impact of systemic diseases on oral health is poorly recognised by patients and other medical professionals. ${ }^{3}$ In this study some patients with HIV reported that, with universal precautions in cross infection control, the risk of transmission of HIV should not be a concern. However, there are associated oral conditions and drug interactions that as dentists we should be aware of. In patients with diabetes we know that the risk of periodontal disease and poor healing is high and this may change our management, for example, shorter recalls. Medical emergencies would be easier to recognise, or even prevent, if the dental team were aware of the diagnosis.

It is of concern that patients were worried about loss of confidentiality and stigma. As a profession we should be asking why patients do not want to tell us about these conditions and it raises the question if there other conditions they are also not disclosing.

\section{Bryan Kerr}

Consultant in Special Care Dentistry

Guy's and St Thomas' NHS

Foundation Trust

King's College London Dental Institute

1. Fenlon M R, McCartan B E. Validity of a patient self-completed health questionnaire in a primary care dental practice. Community Dent Oral Epidemiol 1992; 20: 130-132.

2. Giuliani M, Lagolo C, Rezza G et al. Dental care and HIV-infected individuals: are they equally treated? Community Dent Oral Epidemiol 2005; 33: 447-453.

3. Eldarrat A H. Awareness and attitude of diabetic patients about their increased risk for oral diseases. Oral Health Prev Dent 2011; 9: 235-241.

\section{AUTHOR QUESTIONS AND ANSWERS}

1. Why did you undertake this research? Evidence shows that many individuals do not disclose their medical history to the dentist. This is an issue that impacts on all dental teams at every level. Reasons for lack of disclosure have always been speculative and now the evidence is largely outdated. This research idea was devised to investigate and give understanding to dental practitioners as to why patients do not disclose information to the dentist. This was done by discussing disclosure issues with patients themselves. Knowing why individuals do and don't disclose will allow us as a profession to adapt the way in which we obtain medical histories and communicate with our patients with regard to their diagnosis.

2. What would you like to do next in this area to follow on from this work?

It would be interesting and comprehensive to use this research method to look and compare disclosure of medical histories in other chronic medical conditions, such as hepatitis or coronary heart disease. 